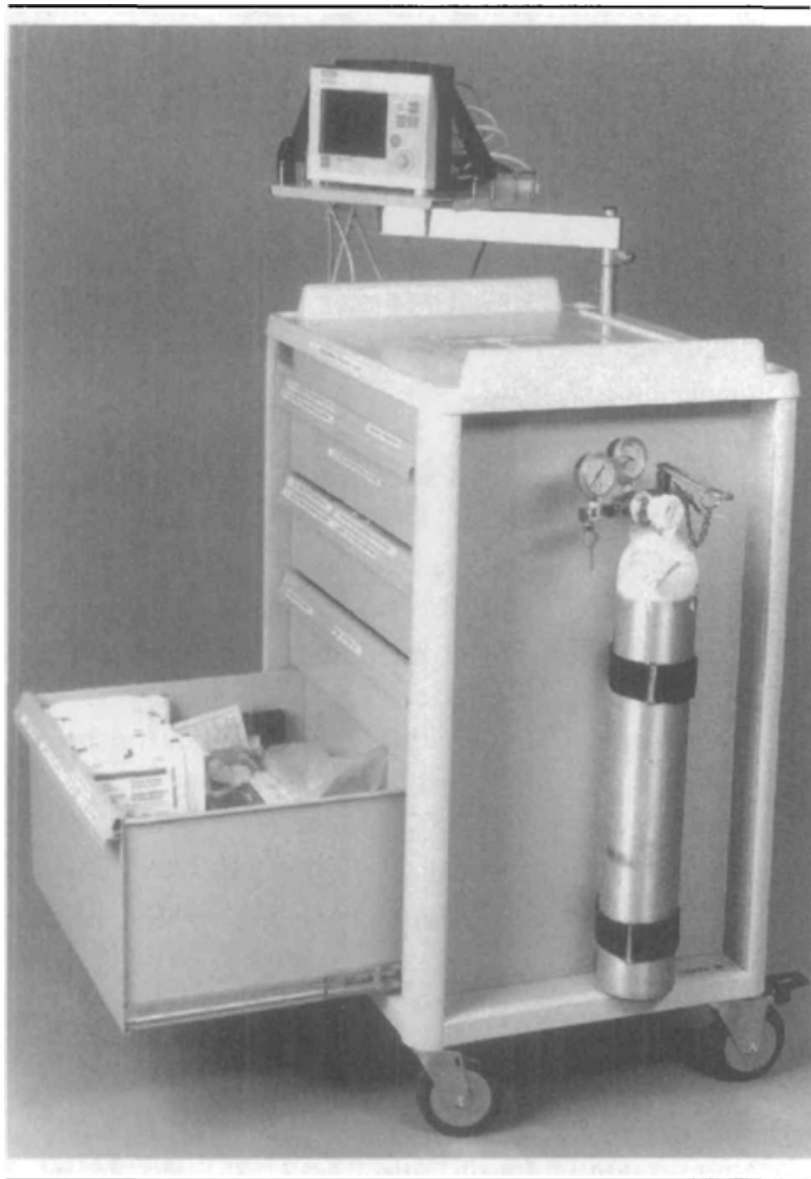

FIGURE Mobile regional block cart, with the portable monitor mounted on the top and oxygen cylinder attached to the side

The cart consists of four drawers on swivel rollers with adjustable locks. The top surface provides a work space for a sterile regional tray set. A portable Siemens ${ }^{\circledR}$ SC 6000 monitor mounted on a swivel arm provides monitoring that can be viewed from a wide range of angles. The cart is stocked with resuscitation and intubation drugs, an $\mathrm{E}$ cylinder of oxygen, equipment to secure an emergency airway, drugs and equipment for peripheral nerve blocks and central neuraxial blocks, an atlas for regional anaesthesia and a data collecting book. The contents of the cart are replenished daily by an anaesthesia assistant responsible for the cart.

All regional blocks are performed in areas with wall suction capability and staffed by nurses who have training in resuscitation and an understanding of regional anaesthesia and its complications. These corrclate to areas of perioperative management: pre-assessment unit (PAU), surgical day care admitting area (SDCU) and postanaesthetic care unit (PACU). The regional block cart has been a successful experience that we would like to share with other medical centres.

Abdullah M. Kaki MB CHB FRCPC

Anne C.P. Lui MD FRCPC

Patricia Holmes RN

Ottawa, Ontario

\section{Postoperative pain management - the ability to cope}

To the Editor:

In a recent editorial, Dr. Moote decried the widespread use of patient controlled analgesia, citing "technology creep." Critical to her argument was the rhetorical question "Is the novice paticnt, with impaired cognitive function really more capable than the veteran nurse, with all faculties intact?" Our reservations about this criticism of modern acute pain management are well encapsulated in a recent publication. ${ }^{2}$ Salmon and Manyande acknowledged that patients usually received less analgesia than they needed and that this had been attributed to the attitude of nurses to analgesia and their ability to assess pain. They went on to explore the hypothesis that patients were reluctant to disclose their difficulty in coping with their pain for fear of being regarded as "demanding" and hence unpopular. In a relatively small study they demonstrated that nurses had difficulty distinguishing pain intensity from the ability to cope.

This formalises our experience. We submit that an important and unsung advantage of patient controlled analgesia is its ability to remove a patient's ability to cope from the loop which determines when they receive analgesia. It is easier to be dignified when one does not have to ask for help. This distinction between pain intensity and coping must be addressed in future research in this area. We appreciate that there are cheaper "lower tech" solutions to post operative pain than PCA. However, they must be consistent with the wishes of the patient for autonomy and self respect.

\section{Bond $M B$ FRCPC \\ Patrick Butler MD FRCPC \\ Department of Anaesthesia \\ Kingston General Hospital, ON}

\section{REFERENCES}

1 Moote CA. Postoperative pain management - back to basics. Can J Anaesth 1995; 42: 453-7.

2 Saimon $P$, Manyande $A$. Good patients cope with their pain: postoperative analgesia and nurses' perceptions of their patients' pain. Pain $1996 ; 68$ : 63-8. 